García-Molano, O.J. (2019). Cocinas tradicionales en declive: riesgo para el patrimonio cultural y la seguridad alimentaria en Guayatá. Revista de Antropología y Sociología: VIRAJES, 21(2), 15-38. DOI: $10.17151 /$ rasv.2019.21.2.2

\title{
Cocinas tradicionales en declive: riesgo para el patrimonio cultural y la seguridad alimentaria en Guayatá*
}

\section{OLGA JUDIT GARCÍA-MOLANO**}

Recibido: 16 de febrero de 2019

Aprobado: 29 de abril de 2019

Artículo de investigación

\footnotetext{
* Artículo derivado de la investigación titulada "Patrimonio cultural y seguridad alimentaria: Tejiendo relaciones en torno a las cocinas tradicionales guayatunas".

** Magíster en Patrimonio Cultural. Grupo de Investigación para la Animación Cultural MUISUATA. Universidad Pedagógicay TecnológicadeColombia.Tunja,Colombia.E-mail:Olga.garcia01@uptc.edu.co. (1) ORCID: 0000-0002-5799-5470. Google Scholar
} 


\section{Resumen}

El objetivo de la investigación fue analizar en una comunidad rural campesina las relaciones que emergen entre cocinas tradicionales y seguridad alimentaria y las transformaciones en estas prácticas culturales. A través de una observación etnográfica y entrevistas semiestructuradas, se identifican los cambios en la relación producción-alimentación desde aspectos como: deterioro y crisis de las economías campesinas, migraciones, transformaciones en la propiedad y uso del suelo. Igualmente, la incidencia de sus ciclos festivos, pues las fiestas marcan el espacio social y están ligadas con los ciclos productivos a través de sus cocinas tradicionales, haciendo evidentes los cambios que se están dando en sus hábitos alimenticios. De ahí la importancia de revitalizar esos procesos de la cultura culinaria inmersos en sus cocinas tradicionales, como un aporte para que a esta comunidad se le garantice su seguridad alimentaria y no se pierda este patrimonio a través del cual, han generado lazos de identidad y fraternidad.

Palabras clave: patrimonio cultural, seguridad alimentaria, cocinas tradicionales, cultura alimentaria.

\section{Traditional food in decline: risk to cultural heritage and food safety in Guayatá}

\section{Abstract}

The objective of this research was to analyze the relationships that emerge between traditional food and food safety in a rural peasants' community and the transformations in these cultural practices. Through an ethnographic observation work and semi-structured interviews, changes in the food-production relationship are identified from aspects such as: deterioration and crisis of the peasant economies, migrations, property transformations and land use. Likewise, the incidence of their holiday cycles is identified since holidays mark the social space and are connected to the productive cycles through their traditional foods, making evident the changes that are taking place in their eating habits. Hence, the importance of revitalizing those food culture processes which are immersed in their traditional food as a contribution to ensure that this community is guaranteed food safety and do not lose this heritage through which identity and fraternity bonds have been generated.

Key words: cultural heritage, food safety, traditional food, food culture. 


\section{Introducción}

I n la conciencia colectiva de una comunidad el patrimonio es entendido como cosas heredadas, ya sea objetos materiales o saberes que se han transmitido por generaciones. El patrimonio cultural se ha conceptualizado desde miradas académicas y científicas, como: "El conjunto de manifestaciones u objetos nacidos de la producción humana, que una sociedad ha recibido como herencia histórica" (Llull-Peñalba, 2005, p. 181); "un campo de significación y valoración de objetos y prácticas" (Ariño, 2012, p. 2); "proceso cultural que implica negociación de la memoria, identidad y sentido de lugar" (Smith, 2011, p. 451); "un cohesionador y espacio de enfrentamiento y negociación social, forma de reproducir identidades y diferencia sociales" (Rosas-Mantecón, 1998, p. 6). Por tanto, el patrimonio se refiere a esos aspectos que le permiten a una comunidad identificarse, a la vez que diferenciarse, un nexo con el pasado que pervive en el presente, espacio de disentir y negociar. Para una comunidad el patrimonio es reflejo de sus raíces, sus procesos históricos y su realidad actual, la comunidad otorga un valor simbólico a sus prácticas culturales, ya que las vive y las construye.

En tal sentido, "las sociedades locales han llegado a identificarse e incluso, a definirse patrimonialmente a través de los alimentos y los platos que seleccionan, cocinan y comen" (Medina, 2017, p. 107). Es claro, que los alimentos son vitales para la continuidad de una sociedad y el desarrollo de su cultura, a través de estos las comunidades simbolizan sus creencias, tradiciones y sus intercambios culturales. Entonces, como lo expone la Política de Cocinas Tradicionales de Colombia, las tradiciones culinarias constituyen un patrimonio cultural, son colectivas, pertenecen o identifican a un grupo social, son transmitidas como legado o tradición cultural y hacen parte de la memoria colectiva.

Las tradiciones culinarias, como manifestaciones colectivas, se transmiten de generación en generación, por tanto, la tradición es el comportamiento del presente que le da sentido a los elementos relevantes del pasado (Lenclud, 1987). La tradición se transmite de acuerdo con la funcionalidad para los grupos sociales, "representa continuidad cultural [...] está en constante renovación, se crea, recrea, inventa y destruye cada día" (Arévalo, 2004, p. 926). Como representatividad social la tradición no se limita solamente al pasado, es una combinación de factores de tiempo, pasado y presente. Por tanto, la "parte de la cultura seleccionada en el tiempo con una función de uso en el presente sería la tradición" (Arévalo, 2004, p. 927). Es así que las tradiciones culinarias constituyen la cultura alimentaria de una comunidad. Como lo expone Espeitx (2004): 
El concepto de cultura alimentaria hace referencia al complejo entramado de prácticas y conocimientos, valores, creencias, técnicas y representaciones sobre que, cómo, cuándo, con quién y por qué se come lo que se come en una determinada sociedad (...) la cultura alimentaria incluiría productos y técnicas de producción o elaboración valores, creencias, usos, costumbres y formas de consumo que se le asociarían. (p. 195)

Una comunidad expresa su cultura alimentaria por medio de ritos y prácticas desarrolladas en la preparación y consumo de alimentos, la cultura alimentaria está ligada a un territorio, al sitio donde nacen las personas que poseen los saberes, al entorno en que crecen, a un tiempo y lugar determinado. Es decir, una comunidad manifiesta esta cultura a través, saberes, costumbres, rituales y reglas, expresadas en la cotidianidad de su alimentación y también en momentos de fiesta y celebración. La cocina es un espacio de comunicación por medio de preparaciones del saber culinario. Por consiguiente:

Los universos construidos por cada grupo humano permiten pensar su identidad amarrada directamente a diversos sabores, colores, olores, texturas, sonidos y pensamientos en los cuales hombres y mujeres recrean cotidiana y extraordinariamente su sentido de pertenencia a unos referentes propios llenos de significados. (Salazar, 2001, p. 92)

En tal sentido, las manifestaciones del patrimonio cultural en torno a la cocina tradicional comprenden un "complejo sistema que incluye historia, valores, narrativa, técnicas, creatividad, y en especial referentes de identidad y pertenencia de las personas a un lugar y una comunidad" (Ministerio de Cultura, 2012, p. 22); es decir, la cocina tradicional refleja historia social y familiar y no es ajena a cambios que surgen en el ámbito social, político y económico de la misma. La cocina es espacio donde se transmiten estéticas particulares y la relación de estas prácticas culinarias con la cosmovisión, la salud, festividades familiares o comunitarias y celebraciones rituales o religiosas.

Toda comunidad desarrolla su sistema culinario, la preparación de alimentos está asociada a conocimientos y técnicas culinarias, herramientas, muebles, medios y utensilios empleados, tradiciones artesanales, organización y disposición de la cocina en el hábitat, salud alimentaria y otras manifestaciones relacionadas a estos saberes.

Así mismo, a través de la cultura alimentaria es posible conocer características de la vida social, económica y productiva de una comunidad, y evidencia la manera en que las cocinas tradicionales se vinculan a la 
producción, a formas de obtención de productos, trabajo y asociativismo y, por ende, a su consumo.

En tal sentido, conocer y comprender como se garantizan las comunidades su "derecho [...] a tener una alimentación cultural y nutricionalmente adecuada y suficiente" (Aguirre, 2006, p. 14); desde los escenarios culturales, sociales y geográficos en que se desenvuelven, lleva a conocer como garantizan su seguridad alimentaria. Entendiendo que la "seguridad alimentaria existe cuando todas las personas, en todo momento, tienen acceso físico y económico a suficientes alimentos inocuos y nutritivos que satisfacen sus necesidades dietéticas y preferencias alimentarias para una vida activa y saludable" (Food and Agriculture Organization [FAO], 2008, p. 1).

En tal sentido la seguridad alimentaria "hace parte del sistema sociocultural de la alimentación contemporánea con una dimensión estructural y una dimensión simbólica"1 (Carrasco, 2008, p. 39). Es decir, la seguridad alimentaria es esa condición que refiere una realidad en la que conviven formas de comprender la alimentación y los problemas alimentarios.

Por tanto, la seguridad alimentaria se asume aquí, como el derecho de los pueblos a producir sus alimentos respetando la identidad cultural y la diversidad de los modos de producción, consumo y comercialización agropecuaria, fortaleciendo mercados locales, de tal manera que puedan tener acceso a alimentos en cantidades suficientes y les permitan desarrollar una vida sana, mediante el aprovechamiento de sus recursos soportado desde lo ambiental, económico y social. A partir de la realidad alimentaria de la población y de ese conjunto de circunstancias que determina el desarrollo económico del país.

Por consiguiente, la cultura alimentaria de un pueblo, evidenciada en sus cocinas tradicionales está ligada a su seguridad alimentaria. Una comunidad campesina a través del oficio de sus cocinas tradicionales, alrededor de sus cultivos de pan coger, las huertas caseras y la crianza de animales domésticos se garantiza su seguridad alimentaria.

Se analizan los cambios en la relación producción-alimentación y las transformaciones que se generan en las prácticas culturales relacionadas con

\footnotetext{
${ }^{1}$ Se reconocen cuatro dimensiones para alcanzar los objetivos de la seguridad alimentaria: la disponibilidad de alimentos, es decir, la existencia de cantidades suficientes de alimentos con la calidad adecuada. El acceso a los alimentos, considerado como el acceso de las personas a los recursos adecuados para adquirir los alimentos apropiados y una alimentación nutritiva. La utilización biológica de los alimentos para lograr un estado de bienestar nutricional en que se satisfagan todas las necesidades fisiológicas. Y, por último, la estabilidad, entendida como la garantía de toda persona a tener alimentos adecuados en todo momento, acorde con sus preferencias culturales.
} 
la alimentación desde la dificultad que presentan actualmente las economías campesinas; el deterioro del medio ambiente que ha generado pérdida de especies vegetales y animales, desplazamientos de las poblaciones rurales a las ciudades y envejecimiento de la población. Así mismo, desde la incidencia de sus ciclos festivos, a través de las cocinas tradicionales, donde se hacen evidentes los cambios que se dan en los hábitos alimenticios en la comunidad.

\section{Metodología}

El presente estudio privilegió el enfoque cualitativo, en busca de profundizar y analizar los conocimientos y valores que comparte un grupo de personas que habitan un mismo territorio. Para el análisis propuesto sobre las dinámicas sociales, políticas, económicas y culturales que se desarrollan en torno a las cocinas tradicionales como patrimonio cultural de una comunidad y su seguridad alimentaria, fue seleccionada la vereda Chitavita de Guayatá, ubicada en la región central de Colombia

El estudio se basó en información de primera mano, que se obtuvo en visitas con permanencia de cuatro a seis días seguidos por visita; el contacto inicial se estableció mediante conversaciones, lo que abrió la puerta para conocer y entrar en confianza con los habitantes de la vereda; se generaron espacios que permitieron la observación participante en escenarios como casas de habitación de algunas personas, donde fue posible evidenciar modos de vida, costumbres alimenticias, relaciones con sus vecinos, participación en las fiestas y formas de preparación de alimentos, especialmente aquellos que suelen consumir en días festivos. El contacto directo generó acercamiento y confianza para hablar en profundidad. Se desarrollaron entrevistas abiertas relacionadas con las transformaciones de los ciclos de cultivo, afectación de la población desde la construcción de la represa de Chivor ${ }^{2}$, sus hábitos alimenticios, sus fiestas, relaciones en la vereda, migración de sus habitantes y el problema de envejecimiento de la comunidad. En total fueron 19 entrevistas, 16 a personas de la vereda y tres a habitantes del casco urbano, que facilitaron entender cómo se visualiza la comunidad desde una óptica diferente a la propia.

Las entrevistas incluyeron la profesora de la escuela, quien vive en el casco urbano del municipio, su labor docente y contacto permanente con los niños y la comunidad permitió conocer de cerca las afectaciones por la disminución de la población infantil. Se entrevistó a la persona encargada

\footnotetext{
${ }^{2}$ Embalse creado para proporcionar potencial hidráulico a la central hidroeléctrica de Chivor, ubicado en la región del Valle de Tenza en el departamento de Boyacá, Colombia.
} 
de preparar alimentos en la escuela, un diálogo para evidenciar, qué comen los niños y de qué manera el hecho de comer allí está afectando la comensalidad familiar. Fueron entrevistados, el presidente de la Junta de Acción Comunal (JAC) veredal, varias parejas de campesinos dedicados a las labores agrícolas, entre los que se destaca una pareja de jóvenes esposos, teniendo en cuenta que son contados los hogares con niños pequeños y se entrevistaron personas foráneas que se han establecido en la vereda entre los que se encontró un guayatuno que habitó por varios años en España y regresó para establecerse en su tierra y se dedica a la caficultura, introduciendo nuevas prácticas culturales en la comunidad.

En las entrevistas, fue posible revelar las relaciones que se tejen entre el patrimonio cultural de sus cocinas tradicionales y su seguridad alimentaria, relaciones que se expresan en un territorio con diversos esquemas de propiedad y uso del suelo a través de los ciclos productivos, por medio de la producción y los sistemas de distribución e intercambio, pero también de la comercialización de los productos y los ciclos festivos, donde la comunidad expresa valores, costumbres, tradiciones, lenguajes y símbolos, y cómo en medio de las diversas expresiones de la cultura alimentaria fortalecen unos hábitos alimenticios, a través de los que la comunidad establece reglas en la comensalidad. Evidenciando que si estas expresiones culturales desaparecen, en cierta forma se afecta su seguridad alimentaria.

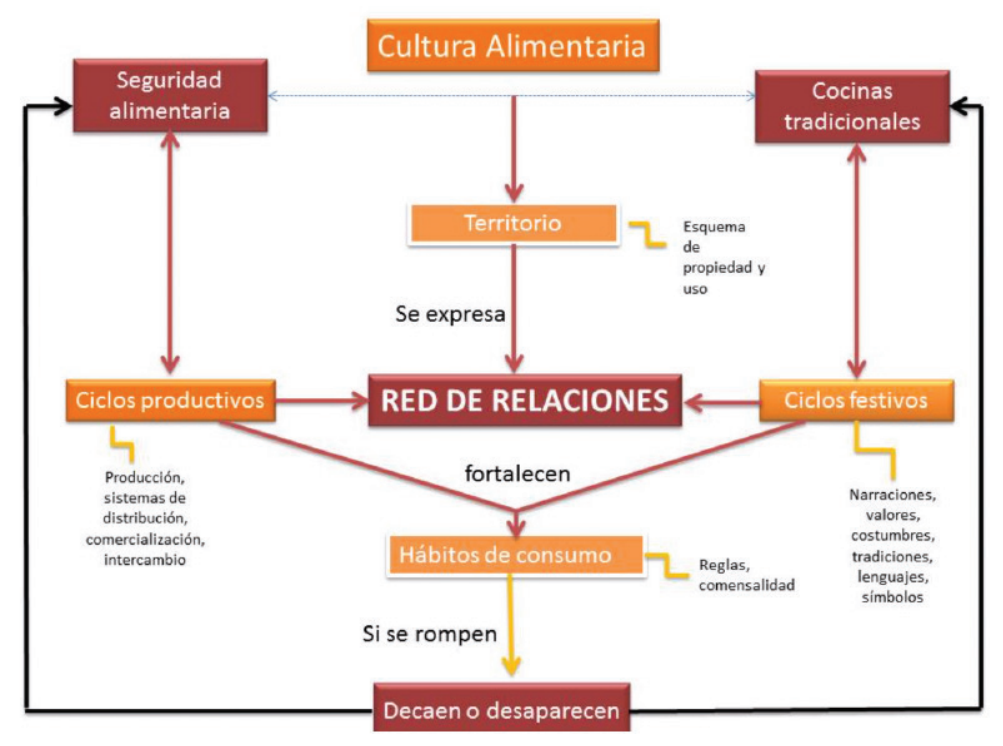

Figura 1. Matriz red de relaciones. Fuente: García (2017) 


\section{La comunidad de Chitavita: Somos los torce lazos}

El municipio de Guayatá está conformado por el casco urbano y 29 veredas. Este territorio evidencia la problemática generalizada en el departamento con respecto a la tenencia de la tierra, Boyacá es el departamento en "donde se presenta el mayor número de predios en minifundio" (Pérez-Martínez y Pérez- Correa, 2002, p. 40).

La situación de fragmentación de terrenos en Guayatá se ha dado por la sucesión de grandes fincas a herederos, quienes deciden parcelar, por lo tanto, existen predios cuyas áreas son inferiores a las establecidas como unidad agrícola familiar.

Chitavita no es ajena a esta situación, a pesar de que algunos de sus pobladores son dueños varios terrenos, se da poca producción agrícola, en contraste con los años en que esta región era reconocida como despensa agrícola de la capital del país.

En la vereda hay 45 unidades habitacionales, de las cuales 32 están habitadas. Se identificaron cuatro grupos de habitantes: campesinos que nacieron y han vivido toda la vida en la vereda, campesinos que nacieron ahí, pero salieron por años a otros lugares del país y con el tiempo han vuelto a habitar la vereda, campesinos que van y vuelven, es decir, habitan la vereda por un tiempo y van a otra ciudad por un tiempo y habitantes foráneos, personas que han llegado al territorio hace dos, 15 o 20 años, buscando un lugar apacible para vivir, y se quedaron. Han logrado integrase e interactuar con los demás grupos.

Pese a ser una comunidad heterogénea, han logrado tal grado de cohesión que les permite unirse para trabajar en busca de beneficios comunes, compartir en las festividades, estar pendientes de la salud de sus vecinos, intercambiar o brindar parte de la cosecha, estar al tanto de cuanto acontece en la vereda.

Si bien son un híbrido cultural, los chitaviteños hacen a un lado sus diferencias y desavenencias a la hora de unirse, ellos tienen claro que ante los demás son como uno solo. Allí se ha unido el carácter social de los foráneos, personas de diferentes partes del país, con algún nivel de formación profesional que vivieron en ciudades grandes y llegaron buscando cambiar el entorno en que desarrollan sus vidas. Unidos a la afectuosidad y sentido de pertenencia de los que se han ido, pero volvieron, criaron sus hijos y regresan para quedarse a pasar los días en su tierra; se mezcla con el arraigo que expresan los que se van, pero vuelven, la tierra los llama, vienen por la siembra, la fiesta, los amigos, la familia. El soporte de esta mezcla cultural lo dan quienes han estado siempre, campesinos amplios, amables y trabajadores apegados a su tierra. Esta amalgama de 
características hace de los chitaviteños una comunidad abierta, espontánea, hospitalaria, que disiente, pero concilia, tratando de sobrellevar unidos los avatares de la vida, esa vida que los ha unido en un mismo territorio.

La comunidad de Chitavita tuvo como una de sus actividades principales la elaboración de lazos, oficio posiblemente de origen prehispánico, con la entrada de los españoles las matas de fique se usaron para elaborar costales. Es por esto, que la población en general los empezó a llamar los torce lazos. Una manera como los foráneos han logrado integrarse y hacer parte de esta comunidad es a través de la identificación que sienten con este apelativo. Uno de los nuevos habitantes lideró algunas de las transformaciones de la vereda, cuando al hacer parte de la JAC, desde sus inicios y junto con la comunidad, institucionalizaron la celebración del día de la raza como día de la vereda y retomaron el apodo. Esta comunidad legítima su derecho a una identidad colectiva, a través de su memoria hay intencionalidad, fijación, van creando asociación con aquello que los identifica como grupo, para el caso la actividad de torcer lazos, a pesar de no practicarla.

El fique fue un cultivo representativo que ha desaparecido al igual que las personas que lo trabajaban, sin embargo, la agricultura sigue siendo la principal fuente económica, las familias que cultivan son pocas, son adultos mayores sin fortaleza para labrar la tierra, han quedado solos, sus hijos han migrado a otras ciudades. Es posible ver cultivos de café, caña de azúcar, maíz, lulo, frijol railón, constituyendo el ingreso económico en algunos hogares. Los cultivos son pequeños, por ende, las cosechas alcanzan unas arrobas, es el caso del café, producto que sobresale en la vereda, la Federación de Cafeteros ha promovido la renovación de plantas viejas entregando a los campesinos nuevas plantas para sembrar. En otros casos, se ven pequeñas parcelas de arracacha, yuca, árboles de cítricos, papayas, plátanos y chirimoyos con los que las familias proveen su alimentación, aunque los frutales están viejos y enfermos, la mosca y otros factores hacen estas frutas no comestibles o de baja calidad, por lo que no vale la pena cosecharlas. Sin embargo, las hortalizas, como espinacas, guatilas, ahuyamas entre otras, son cultivadas en las huertas y hacen parte de su alimentación.

La cría de animales se concentra en aves de corral, por la facilidad para criarlos y comercializarlos o para su consumo en familia. En el caso del ganado es escaso, dada la topografía del terreno, que se caracteriza por ser montañosa, hace difícil la crianza y levante de estos animales. Algunos habitantes de Chitavita no realizan actividades agrícolas, dependen económicamente de una pensión u otros ingresos; dedican sus parcelas a diseñar y mantener los jardines que rodean sus casas. Introducen 
otras prácticas en el uso del suelo, que modifican el paisaje rural y el acceso y circulación de alimentos de autoconsumo.

Los habitantes consideran el turismo como medio para activar la economía y están adecuando sus propiedades para venderlas como lugares de descanso o para proyectos turísticos. En este sentido, en Guayatá se hacen evidentes los lineamientos del gobierno nacional en cuanto al turismo, motor de desarrollo para las regiones, los mismos habitantes consideran que una forma de fortalecerse económicamente es con la llegada de turistas, se generarían nuevos ingresos, y un crecimiento de la población. Para los guayatunos, la llegada de nuevos habitantes es considerada una manera de repoblar el municipio, especialmente en las veredas, ellos son conscientes del envejecimiento que se está dando entre su comunidad. Hay escasez de mano de obra para trabajar en el campo y la afectación económica es cada día sentida.

Los chitaviteños han establecido como lugar de encuentro y reuniones La escuela, espacio de significación social. Además de ser centro educativo para cuatro niños de la vereda, es lugar de reuniones de la JAC y sitio para realizar el bazar el día de la raza. Allí se reúnen también para elaborar carrozas con las que compiten en las ferias y fiestas a San Isidro, realizan encuentros deportivos y reuniones sociales.

La escuela es el espacio donde, en época de fiesta, elaboran platos de sus cocinas tradicionales, aquellos que conllevan un alistamiento, una técnica, un ritual y mayor tiempo de elaboración. En la fiesta comparten al calor de una carne al caldero, plátanos al fondo, masato o chicha, sus tradicionales mogollas, los cabuyos, arepas, pan de maíz, tortillas de sagú y colaciones. Así mismo, en el día a día los chitaviteños preparan sus alimentos, su dieta contempla un sudado de guatila con plátano y carne o gallina, una colada de sagú, una tortilla de sagú, fríjoles, sopa de ahuyama, torta de espinacas, changua con huevo, jugo de naranja o mandarina y, por supuesto, no puede faltar la mogolla para acompañar el café o el chocolate. Platos elaborados con productos de sus cosechas. 


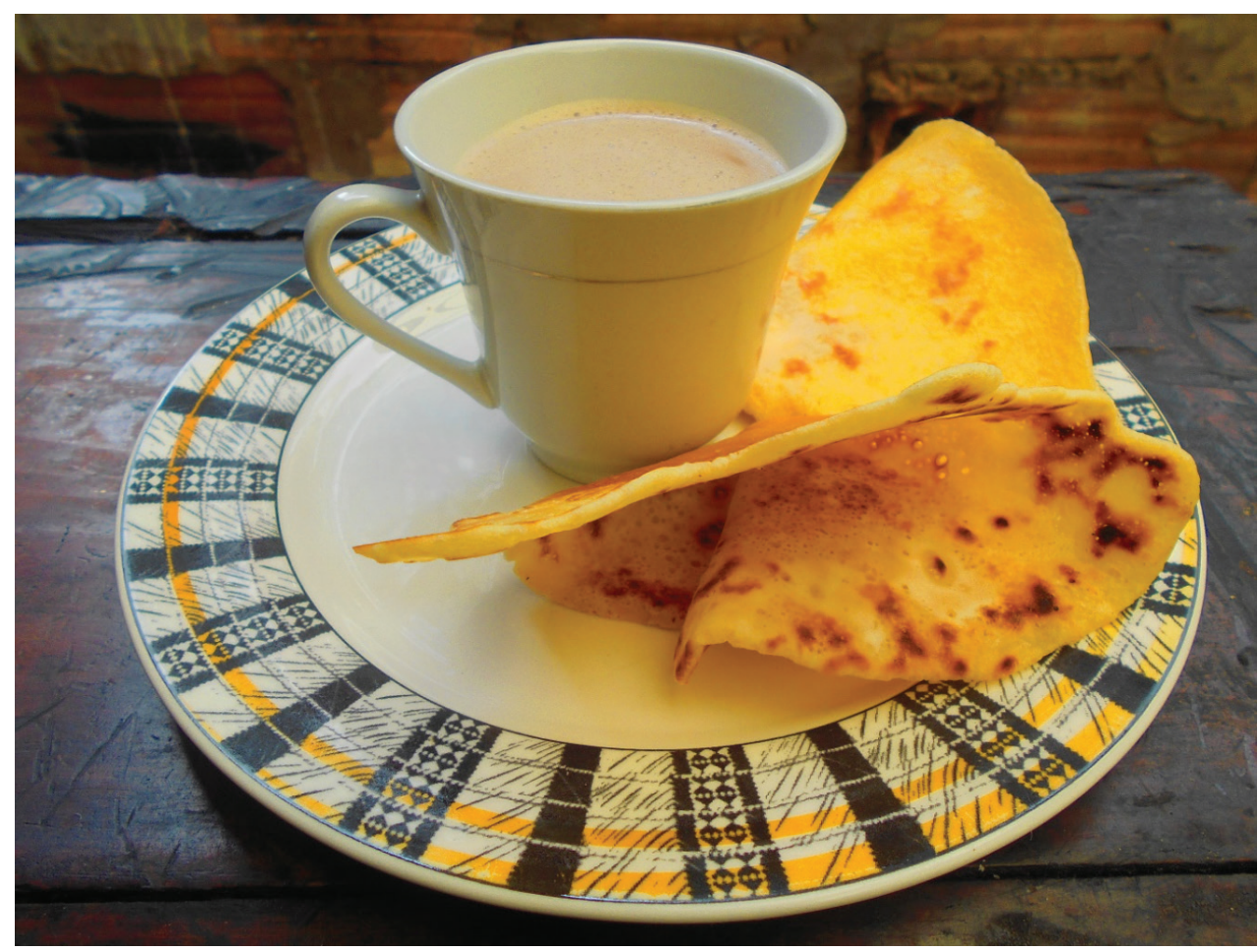

Figura 2. Tortilla de sagú. Fuente: García (2017)

Relaciones que se tejen en torno a las cocinas tradicionales y la seguridad alimentaria

La agricultura campesina y familiar es un sistema de producción que hace parte de la cultura en las comunidades campesinas. El sistema productivo de la comunidad de Chitavita se caracteriza por ser un trabajo familiar, en su desarrollo utilizan pocos insumos y la tecnología utilizada la aporta la tradición, ellos producen para el autoconsumo. Cultivan el huerto casero con hortalizas y aromáticas, en cuanto las parcelas se encuentran cultivos de café con sombrío de las variedades castillo, tabi o común, lo siembran en medio de plantas de plátano, papayas, cítricos y otros árboles para favorecer su desarrollo. El café es el único producto que no consumen de su cosecha, la producción es mínima y el proceso dispendioso, por lo que han buscado asociarse para bajar los costos y lograr resultados a la hora de comercializar.

También siembran plátano de las variedades jamaico, popocho y caturro y caña de azúcar. En época de cosecha concentran la producción 
para el proceso de molienda de caña en la enramada comunitaria donde tienen el molino y extraen la miel y elaboran la panela. Dependiendo la cosecha, venden miel y panela en el municipio vecino, supliendo primero sus necesidades familiares.

Las familias también crían animales domésticos como gallinas, cerdos y vacas, aunque en la vereda no se desarrolla la actividad pecuaria de manera comercial, estos animales son criados para el consumo familiar.

En Chitavita es posible evidenciar que según Contreras y García (como se citaron Meléndez y Cañez, 2008) "los sistemas alimentarios son realidades dinámicas, en las que se dan elementos de continuidad y de cambio a partir de la evolución de procesos sociales que delimitan las formas en que los alimentos son producidos, distribuidos y consumidos" (p. 272). En tal sentido, los chitaviteños mantienen su saber en torno a las preparaciones de sus cocinas tradicionales, ellos con el fruto de sus cosechas, la crianza de animales domésticos, el intercambio de productos con sus vecinos garantiza su seguridad alimentaria; sin embargo, las afectaciones que se están generando en sus ciclos de cosecha están mermando la calidad y cantidad de las mismas.

\section{Deterioro y crisis de las economías campesinas}

Las afectaciones en el deterioro y crisis que están tendiendo las economías campesinas por la fusión de los diversos mercados mundiales, está generando conflictos entre la agricultura campesina y las industrias alimenticias multinacionales. Crisis que se da por el acelerado crecimiento de la población, lo que ha llevado a desarrollar tecnologías nuevas para una agricultura industrial que supla las necesidades de la población, este tipo de agricultura no permite al campesino competir en igualdad de condiciones, la "utilización de tecnologías sofisticadas y caras que expulsan a los productores tradicionales quienes no pueden pagar el costo del paquete tecnológico" (Aguirre, 2006, p. 15).

En Chitavita se evidencia esta realidad nacional. Para el campesino no es fácil competir con grandes productores en condiciones de calidad y cantidad, por lo tanto: "el mercado puede excluirlos, si el consumidor no demanda sus productos al considerarlos caros, un riesgo para la salud, o carentes de calidad, o porque su presentación no es atractiva" (Andablo y Hernández, 2008, p. 201). 
Por otra parte, el cambio en el clima fue una de las situaciones que afectó notablemente la economía. La construcción de la represa de Chivor en los años 70, afectó el clima, según los campesinos la temperatura varió siete grados, generando cambios en la producción agrícola y, por ende, la economía local. Los cultivos mermaron, las grandes parcelas de tomate, cacao, cítricos y otros frutales con el tiempo se fueron deteriorando, su dieta se fue transformando en la medida que tuvieron que cambiar los tipos de cultivos y se alteraron sus prácticas culturales. El calentamiento global también ha transformado los ciclos productivos, las épocas de lluvia ya no son las mismas, el campesino no sabe cuándo sembrar, para ellos el comienzo del invierno era indicador para iniciar la siembra, el verano era el momento de cosechar. Es tal el grado de afectación de las cosechas, que a veces no recogen ni para el consumo.

Estos factores han contribuido al deterioro de la economía campesina, la cual está constituida por lo que cosechan y crían, afectando la seguridad alimentaria en los hogares de esta comunidad, ellos a lo largo de su vida y a través de sus procesos culturales han desarrollado un gusto por comer lo que saben cultivar.

Otra afectación es el envejecimiento de la población, situación presente en todas las regiones colombianas. Se evidencia con énfasis en las zonas rurales, dadas las condiciones de vida de esta población y puesto que "la mayor incidencia de la pobreza en personas mayores rurales puede tener como consecuencia la presencia cada vez más numerosa población adulta mayor rural con algún grado de dependencia y vulnerabilidad" (CEPAL, 2004, p. 1). El envejecimiento en la comunidad chitaviteña se ha ido dando por cambios en la configuración de las edades y movimientos migratorios a la ciudad de la población joven; el retorno al lugar de origen en la vejez y la llegada de personas mayores que ven en este territorio un espacio de descanso. Algunos habitantes han llegado a la vereda porque "vivir y envejecer en el pueblo trae consigo ventajas innegables que devienen sobre todo de un proceso gradual de la pérdida de actividad y de proximidad y frecuencia de contactos con las redes sociales próximas (familia y vecindario)" (Rodríguez, 2004, p. 3). Esta migración a zonas rurales de personas mayores de 60 años, afecta la economía campesina, está generando envejecimiento doméstico y disminución de mano de obra para labrar la tierra o realizar las actividades del campo, ya que además, concentra la población adulta en la vereda. 


\section{Cambios en la propiedad y uso del suelo}

En la vereda se da singular estructura de la propiedad y uso del suelo, la forma de tenencia de la tierra tiene que ver con el uso que ellos le dan. Está la finca para la vivienda, con uso exclusivo como lugar de habitación. Destacan fincas pequeñas habitadas por una mujer, y cuya característica principal son hermosos jardines, es mínimo lo que cultivan para el consumo. Hay fincas habitadas esporádicamente, sus dueños las tienen para descansar, compraron para pasar días festivos o vacaciones, situación que hace evidente el:

Cambio del uso del suelo en donde la tierra (como medio de producción) antes dedicada al cultivo se convierte en mercancía para su lotificación y venta, cuyo atractivo es estar cerca del campo fuera de las incomodidades de la vida en la ciudad. (Meléndez y Cañez, 2008, p. 288)

El mayor número de predios lo constituyen fincas para la cosecha, habitadas por campesinos y algunos foráneos. En el caso de los campesinos, las fincas cuentan con una pequeña huerta y algunos animales domésticos, con los que proveen parte de su alimentación. Aunque no siembran en grandes cantidades, pues la fuerza de trabajo es escasa, en estos terrenos sobresalen cultivos de café, y en menor cantidad caña de azúcar, maíz y lulo. Y existen fincas deshabitadas, son de personas que se han ido para el casco urbano o para otra ciudad. En Chitavita el cambio en la propiedad y uso del suelo afecta la agricultura y otras actividades menores como, la ganadería y la artesanía. En consecuencia "esa estrategia multiusos a través de la cual los campesinos mantienen y reproducen sus sistemas productivos, que constituye una característica valiosa que tiende a conservar los recursos naturales manteniendo la diversidad medioambiental y biológica" (Toledo, 1993, p. 5), pierde sentido en cuanto la población campesina está desapareciendo y quienes la están reemplazando, desconocen la sabiduría ecológica del productor campesino tradicional, ya que el nuevo uso del suelo no se orienta hacia las cosechas, por el contrario las están abandonando o cambiando por otras actividades económicas. 


\section{Migración de la población campesina a las ciudades}

La situación de violencia que ha vivido el pueblo colombiano en los últimos 50 años ha generado afectaciones de tipo social, económico, cultural y político. Tal situación no ha sido ajena para la comunidad de Chitavita, Guayatá es un municipio ubicado al oriente de Boyacá en límites con el departamento de Casanare, posición que favoreció la presencia de grupos armados ilegales y la siembra de cultivos de uso ilícito. Las condiciones de violencia que se viven en el sector rural han afectado de manera negativa las economías campesinas, sus producciones agrícolas y pecuarias se ven mermadas, para el campesino es difícil sacar sus productos al mercado, disminuyendo las posibilidades de crecimiento del sector rural y generando que la población migre en busca de seguridad y otras posibilidades económicas.

Otro factor que ha generado acciones de salida de la población, es el trabajo en las minas de esmeraldas de Chivor. Los jóvenes ven en esta actividad un medio para obtener ingresos de manera rápida, y aunque aquellos guayatunos que salieron hace años a excavar las minas saben lo difícil del trabajo, y no quieren que sus hijos lo hagan, la situación se sigue presentando. Finalmente, las personas migran con anhelos de mejores formas de vida y otros niveles de educación.

Esto lleva a la población, especialmente joven ${ }^{3}$ a migrar buscando horizontes seguros y garantías de desarrollo personal. A pesar de contar con mayor cobertura en servicios básicos y educativos, la crisis de la economía campesina, genera desplazamiento de la población joven a las ciudades, cuando en el campo se carece de oportunidades y condiciones que les permitan obtener ingresos económicos, o poder continuar estudiando. En Guayatá no hay universidades, los jóvenes cuando se gradúan del colegio y tienen posibilidades, viajan a ciudades como Bogotá o Tunja; ellos regresan en época de vacaciones, pero difícilmente se establecen en Guayatá para trabajar y formar un hogar. Al mismo tiempo, las nuevas políticas que se implantaron en Colombia con los procesos de apertura económica en la década del 90, trajeron la implantación del "modelo neoliberal que asigna a la sociedad rural, a la economía campesina y a la pequeña comunidad la función de proveedores de mano de obra para actividades económicas urbanas" (Pérez-Martínez y Pérez-Correa, 2002, p. 51). De ahí que la gente

\footnotetext{
${ }^{3}$ La juventud rural tiene dos marcadores identitarios generales: uno etario y, por lo mismo, temporal, provisional, y otro socio espacial, fijo, si se quiere, portador y fruto de situaciones y condiciones que sus pobladores no pueden controlar. El segundo marcador, el rural, denota un grupo social marginado que, por esta razón, busca con frecuencia que las nuevas generaciones se trasladen a otros espacios sociales y asuman otros vínculos laborales y otros referentes socio territoriales (Osorio, Jaramillo y Orjuela, 2011).
} 
migre a las ciudades para emplearse en actividades de construcción y ser operarios en fábricas, buscando condiciones económicas favorables.

Los jóvenes no encuentran sentido a la vida en el campo, sus expectativas hacia el futuro no contemplan las actividades agrícolas. Esto revela la falta de pertenencia que existe con respecto a la vida en el campo, por lo tanto, es necesario suscitar espacios de encuentro donde los jóvenes se reconozcan en sus memorias, saberes, historias y oficios. Pues son ellos, "los actores estratégicos en la continuidad de la acción colectiva y las organizaciones, como en la sostenibilidad de las actividades productivas" (Osorio, Jaramillo y Orjuela, 2011, p. 6).

\section{Los ciclos festivos y la cocina tradicional}

En la cultura de una comunidad, los eventos festivos adquieren una importancia fundamental en la reproducción y re-creación del patrimonio de los grupos locales, ya que la tradición se renueva dentro de los cauces del saber tradicional, pero con apertura también a los cambios. En tal sentido:

La fiesta es en sí misma un rito social que permite remarcar un hecho o acontecimiento especial. Tratándose de un rito, la fiesta debe ceñirse a patrones determinados, asumiendo los participantes diferentes roles en concordancia con esos patrones. Música, danza y comida son los acompañantes de este ritual. (Urrutia, 2009, p. 39)

La comida, como representación de identidad colectiva, se hace presente en las fiestas, pues las comunidades suelen destinar ciertas preparaciones culinarias especiales para festividades religiosas, culturales y sociales. Las comunidades campesinas se organizan en torno a un calendario agrícola y religioso, como manera de prever el futuro, equilibrar actividades y organizar su vida. "Las fiestas estructuran el calendario y el espacio de las sociedades" (Urrutia, 2009, p. 38). Por medio de este establecen un tiempo de descanso, momento en que suspenden su cotidianidad para participar en eventos especiales.

En tal sentido, Guayatá tiene un nutrido calendario festivo, de los doce meses del año solamente en febrero no realizan eventos. Sus fiestas van desde rituales religiosos entre las que sobresalen: el Corpus Christi, en el que la comunidad engalana las calles con coloridos tapices elaborados con pétalos de flores, hermosos altares adornados con frutos de la cosecha, en los que la custodia hace estación, mientras fieles rezan y cantan; las ferias y fiestas tradicionales en honor a San Isidro Labrador, reconocidas por congregar el mayor número de visitantes y que antiguamente marcaba 
el inicio de la recolección de la cosecha, pues este tiempo solía darse entre los meses de octubre y enero, cuando entraba el verano. El tercer evento de índole religioso es la fiesta a la Virgen del Buen Consejo patrona de Guayatá, venerada en la iglesia del pueblo y en casas de la vereda, donde es posible ver cuadros y altares de la imagen que evidencian la devoción.

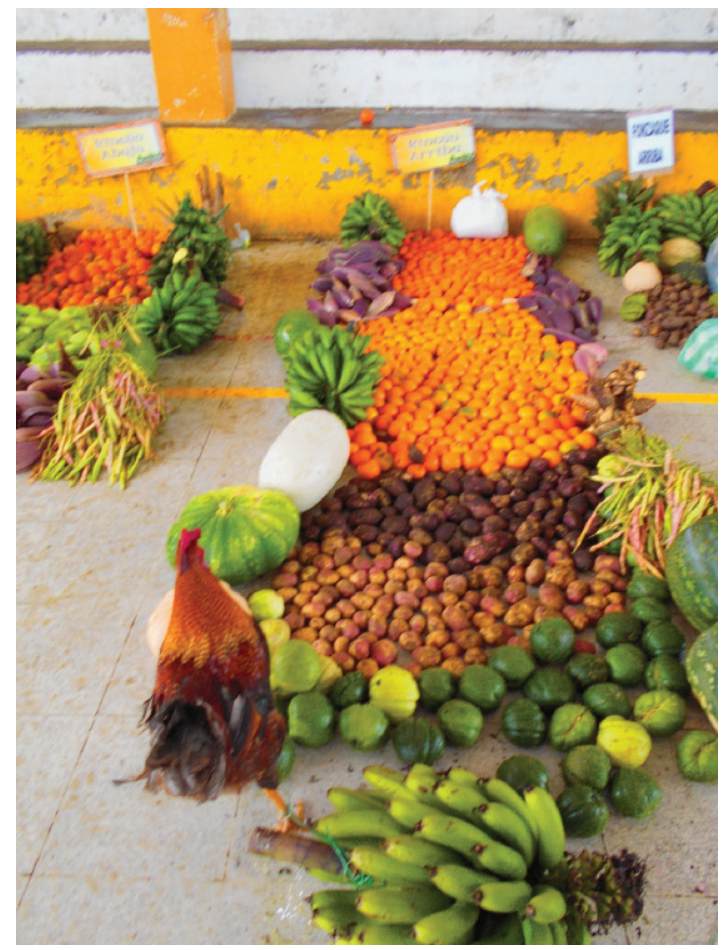

Figura 3. Ofrendas a San Isidro. Fuente: García (2015).

Los chitaviteños participan en festividades culturales como el Festival del café y la Mogolla guayatuna, una manera en que la comunidad honra productos de su cultura alimentaria. En abril conmemoran la fundación del municipio, en mayo las Fiestas de Mitaca que es esencialmente una feria ganadera y porcina. En diciembre el Aguinaldo guayatuno, en el que cada noche en medio de arbolitos y anditas ${ }^{4}$ los guayatunos realizan una procesión hacia el parque del pueblo que termina con el rosario. En el calendario festivo guayatuno se destaca la celebración del día de la raza, actividad propia de la vereda Chitavita, por medio de un bazar la celebran

\footnotetext{
${ }^{4}$ Arbolitos: estandartes elaborados en un marco de madera el que es adornado con diversos amasijos preparados a base de sagú y maíz, pollos criollos cocidos y botellas con alguna bebida alcohólica.
} 
hace 17 años. Esta celebración nació como una forma de exaltar valores culturales en los niños, esta manifestación cultural ha sufrido el impacto de las migraciones de la comunidad, por la disminución de niños en la escuela. La han transformado implementando eventos deportivos; sin embargo, mantienen la tradición de preparar platos de sus cocinas tradicionales, como una forma de generar ingresos para suplir necesidades de la vereda. Es así, como en la fiesta las relaciones sociales se consolidan, sobre todo las que tienen que ver con la autoridad y el poder. En la fiesta las personas se integran, se desvanecen las diferencias sociales, separan la cotidianidad del tiempo de trabajo, se preparan para ver y ser vistos, la fiesta es un espacio para el consumo de alimentos. Sobresale la reciprocidad, intercambio de ofrendas que reafirman relaciones, ya que el acto de comer juntos implica aceptación del otro. La fiesta es también un momento de derroche, no importa gastar, muestran ampliamente su generosidad buscando sobresalir. Los chitaviteños se unen en torno a sus saberes culinarios para proveer alimentos durante la festividad e incluso antes de esta; en época de recolección apartan lo mejor de la cosecha para las ofrendas al santo de su devoción y preparar sus cocinas tradicionales.

Se reafirma cómo las festividades constituyen mecanismos de cohesión social, en donde la comida tiene un papel fundamental en la reproducción de identidad colectiva. Es por esto, que en torno a las fiestas la comunidad de Chitavita va tejiendo unas relaciones que se desarrollan en el escenario de las cosechas, es a través de estas que se vinculan para participar en las festividades religiosas con las dádivas al santo que celebran. En estos espacios y tiempos de fiesta, la comida tiene significación como lo exponen Meléndez y Cañez (2008): "la comida durante estos eventos tenía gran importancia ya que, a su alrededor, se realizaban formas de convivencia y comensalidad con las que se recreaba la identidad colectiva y familiar" (p. 279). La comida es un modo de sentir que están celebrando, es alrededor de un plato especial de comida, donde se da tiempo y espacio para compartir y dialogar. Pero no solo en la fiesta, también todo lo que precede su realización; por ejemplo, en la época de navidad para los aguinaldos, durante los rosarios, la comunidad de Chitavita se reúne y elabora diversos amasijos para adornan los arbolitos con que ofrendan en la noche que les corresponda la celebración. 


\section{Los hábitos alimenticios}

Una comunidad define qué es aquello con lo cual se identifica y por qué lo identifica, ese proceso de identificarse se transmite en ejercicios de encuentros sociales en los que la memoria es el principal actor; en tal sentido "la cocina articula doblemente la identidad de una cultura, está presente en los órdenes biológico, fisiológico y orgánico y a su vez articula el mundo de lo simbólico, de lo significativo, en los aspectos de la representación y el sentido" (Salazar, 2001 p. 93).

El ser humano en el proceso de alimentarse genera entonces unos hábitos alimenticios, producto de una costumbre arraigada en su cotidianidad, dado que, las personas suelen tomar los hábitos alimenticios que tiene el grupo social al que pertenece. Por tanto, hablar de hábitos alimenticios es hablar de "las prácticas alimenticias socioculturales y su representación social en el ámbito familiar" (Oceguera Parra, 2008, p. 153). En Chitavita existen unos hábitos alimenticios formados en espacios sociales principalmente familiares y también colectivos. Los hábitos alimenticios se fortalecen con la transmisión del saber en torno a la preparación de los alimentos, a través, de "las actitudes, valores y creencias con que las personas resuelven diariamente su alimentación, sin desatender los hábitos individuales y costumbres colectivas profundamente arraigadas en la cotidianidad" (Oceguera Parra, 2008, p. 14).

Los chitaviteños han desarrollado desde la niñez, hábitos alimenticios a través de sus cocinas tradicionales. Ellos lo hacen con sus nietos, aunque no vivan en la vereda, aprovechan cuando los visitan para prepárales sus comidas. Entonces las familias inciden en la configuración del gusto, desde la niñez los van involucrando en sus prácticas culinarias y con ello permiten "la construcción del nosotros de pertenencia donde reglas y representaciones tienen valor" (Aguirre, 2006, p. 9). Aunque algunos habitantes de la vereda continúan preparando las comidas familiares, pues es a través de estas que marcan un gusto y una pertenencia, no todos los habitantes de la vereda poseen esos saberes y algunos mayores poco cocinan, y suelen frecuentar algún restaurante del pueblo, situación que va llevando a la pérdida y transmisión de estas prácticas tradicionales.

Los cambios en los hábitos alimenticios tienen que ver con las transformaciones en las prácticas de las cocinas tradicionales, un ejemplo es el sagú, rizoma cultivado y trabajado por los chitaviteños para obtener una harina suave con la que preparaban tortillas y coladas, y que solían mezclar con maíz para hacer varios tipos de amasijos especialmente en épocas de fiesta. La harina de sagú hacía parte de la dieta alimenticia de la comunidad, actualmente en algunas veredas de Guayatá cultivan sagú 
en mínima cantidad, debido al complejo proceso de rallado y lavado para obtener la harina, y el bajo precio que obtienen en el mercado al venderla; entonces su consumo se ha reemplazado por otros productos, y son pocas las personas que saben cómo prepararlo.

Las transformaciones en las prácticas culturales vinculadas con la alimentación de la comunidad, tienen que ver también con las variaciones en las cosechas, cambios en los ciclos productivos están causando afectación directa en los hábitos alimenticios, al no poder consumir lo que producen $\mathrm{y}$ tener que recurrir a otros ingredientes industriales; lo que puede derivar también en un cambio en las comidas especiales que preparan en sus fiestas, afectándose formas de convivencia y comensalidad con las que recrean su identidad cultural.

Igualmente, los hábitos alimenticios de las nuevas generaciones se están transformando en espacios sociales como la escuela, donde el gusto de los niños está cambiando, les brindan una alimentación estructurada por una nutricionista bajo minuta, con alimentos que traen de otras regiones y muchas veces no incluyen lo que sus padres producen en sus fincas. A eso suma el cambio en la comensalidad familiar; es decir, el hecho que los niños no compartan una comida en el hogar con sus padres tiene consecuencias. La"comensalidad hogareña, con todas sus ventajas, negociaciones, jerarquías y desgracias es uno de los momentos importantes en la socialización de los jóvenes y en la elaboración crítica de los sucesos que constituyen 'la realidad' en los adultos" (Aguirre, 2006, p. 24). Esto ha contribuido a modificar el gusto por las recetas familiares, a la vez que ocasiona una interrupción en el saber culinario, si desde la infancia no se transmite el gusto por las cocinas tradicionales, difícilmente el niño aprende a preparar alimentos que no le gustan.

A pesar de los hechos antes mencionados, en Chitavita es posible encontrar una muestra considerable de sus cocinas tradicionales, este saber, curiosamente no es exclusivo de las mujeres, se resalta el hecho de que los hombres son activos a la hora de preparar alimentos, si se trata de participar en las fiestas, ellos saben las recetas de ciertos platos especiales. En días de fiesta se puede apreciar el abanico de sabores que brinda el degustar unos plátanos al fondo elaborados con miel de caña y cocidos lentamente en leña hasta lograr que la miel cale dentro del plátano, o una carne al caldero adobada con hierbas y especias y cocida en chicha de maíz y cerveza, y ¿por qué no? Unos cabuyos, amasijo elaborado con harina de maíz y sagú en horno de leña, amén de otras preparaciones donde los chitaviteños a través de las formas de elaboración de estos platos y la permanencia del gusto por su sabor evidencian su identidad culinaria. 


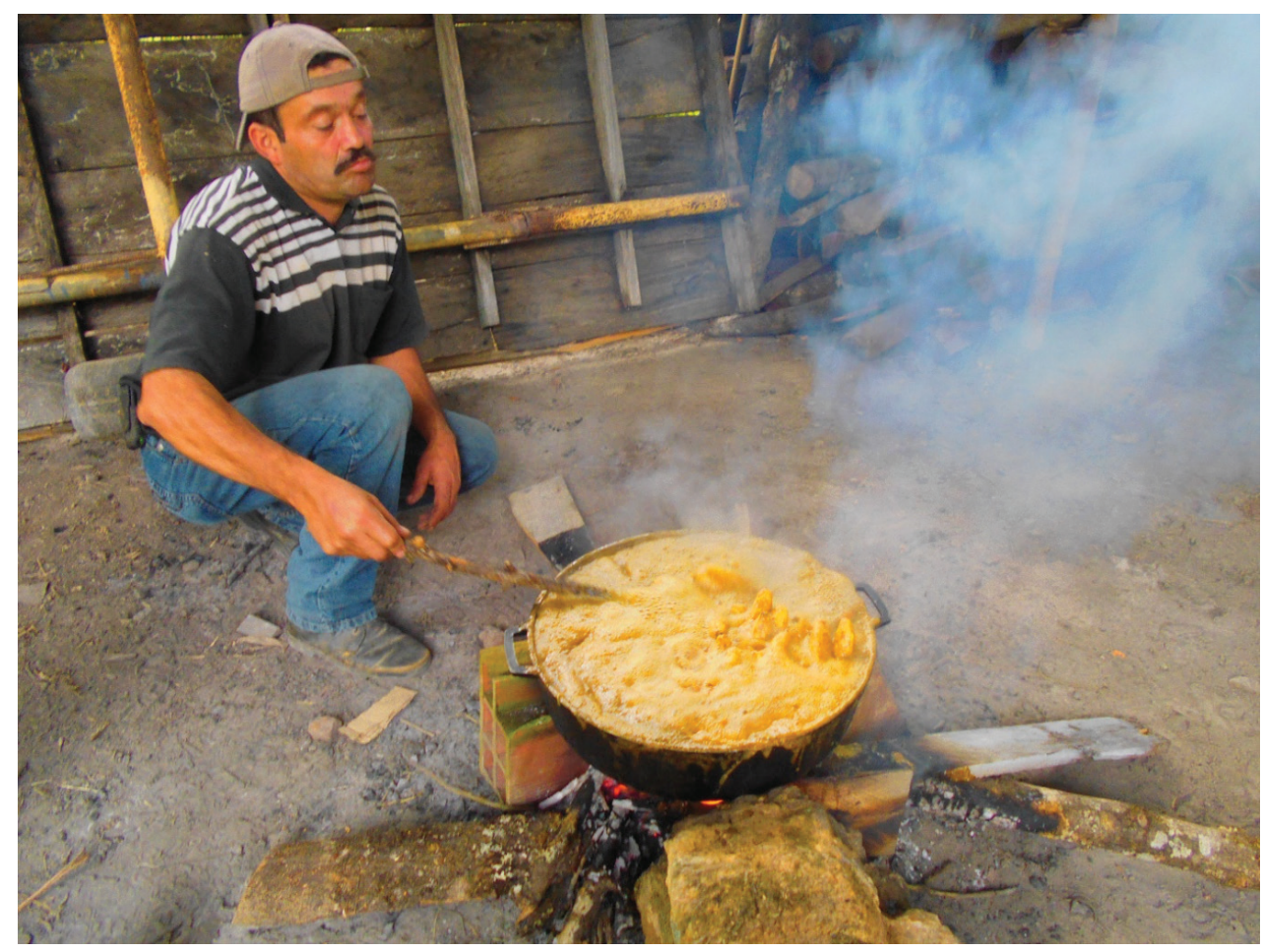

Figura 4. Don Miguel prepara plátanos al fondo. Fuente: García (2015).

\section{Conclusiones}

El riesgo que presenta el patrimonio cultural y la seguridad alimentaria de la comunidad guayatuna tiene que ver con el declive que están teniendo sus cocinas tradicionales. En tal sentido, son varios los factores que amenazan la pervivencia de estos saberes.

Es evidente que las transformaciones en la propiedad y uso del suelo, trae consigo predominio del estilo de vida urbano, cambio paisajístico en el territorio y disminución de producción agropecuaria, generado por la influencia de sus nuevos habitantes.

En las comunidades rurales, la manifestación de sus cocinas tradicionales está inmersa en su vida a través de su dieta alimenticia y en sus festividades. Día a día su existencia se pone en riesgo, porque el saber desaparecerá cuando sus poseedores dejen de existir, ya no se cultiven los productos que requieren para sus preparaciones y el territorio sea habitado por foráneos que desconozcan la riqueza de dichos saberes y por la falta de sentido, lógica y significado por parte de las nuevas generaciones, quienes 
no ven en el campo un escenario propicio para desarrollar su proyecto de vida. En tal sentido, urge crear espacios donde los jóvenes guayatunos fortalezcan su autoestima, se reconozcan en su memoria, sus historias, saberes y oficios, buscando que ellos, los jóvenes, apropien esos saberes que les han permitido a sus padres y abuelos llevar una vida en armonía y sintonía con la naturaleza, de la que se han provisto un sustento y desde donde han abastecido los alimentos para la región y el país.

La pérdida de valores, significados sociales y culturales que la comunidad da a las cocinas tradicionales, se puede dar en la medida que las familias dejen de producir sus propios alimentos, ya sea por abandono del cultivo de los productos básicos de su dieta, o por la cría de animales domésticos que la complementan, conllevando a la pérdida de su seguridad alimentaria. Estimular la producción campesina revitalizará muchas prácticas socioculturales, como las cocinas tradicionales, bien colectivo que se constituye en identidad e historia local, regional y nacional, por medio de las cuales las comunidades revelan la relación mutua entre diversidad biológica y diversidad cultural. Por tanto, la activación del saber, se debe dar en tanto que las cocinas tradicionales son el modelo alimentario propio de un pueblo.

Esta manifestación como referente de identidad colectiva va teniendo trasformaciones y adaptaciones propias que les permite seguir existiendo como experiencia cultural en medio del dinamismo de la vida de sus poseedores. Están abocadas a una crisis si no se fortalece la permanencia de las comunidades campesinas en las zonas rurales. El cese de las migraciones, ante un panorama alentador en el campo para las nuevas generaciones, activaría las economías locales fortaleciendo la transmisión de saberes, mejorando la calidad de vida de las comunidades especialmente desde el ámbito de la seguridad alimentaria.

Finalmente, se debe reconocer la fiesta como escenario de reivindicación cultural de las comunidades, pues es la forma como ellos manifiestan sus saberes, expresiones, sentimientos, agradecimientos, y a través de ellas enseñan sus rituales. Las fiestas son la culminación de un ciclo de cosecha, son el único medio que tienen las comunidades campesinas para exaltar sus cocinas tradicionales; de ahí que en Guayatá la gran riqueza festiva de su calendario sea una razón poderosa para pensar en que esta sea la forma de mantener vivos sus saberes culinarios, reactivar su economía, a la vez que en ellas los guayatunos reafirman su identidad cultural, se integran y refuerzan su solidaridad comunitaria. Por esta razón, las fiestas deben ser reivindicadas como patrimonio cultural etnológico, pues son manifestaciones culturales en continua transformación, donde las comunidades desde su comportamiento en el presente dan sentido a los elementos significativos de su pasado. 


\section{Referencias bibliográficas}

Aguirre, P. (2006). Qué puede decirnos una antropóloga sobre alimentación: Hablando sobre gustos, cuerpos, mercados y genes. Instituto de Altos Estudios Sociales, Universidad Nacional de San Martín, Buenos Aires, Argentina. Recuperado de http://www. fac. org. ar/qcvc/ llave/c027e/aguirrep. php

Andablo, A. y Hernández, M. (2008). Seguridad alimentaria y sus repercusiones para los productores rurales: el caso de la producción campesina de queso fresco en la región centro del estado de Sonora. En S. Sandoval y J.M. Meléndez (eds.), Cultura y seguridad alimentaria (pp. 195-234). Madrid, España: Plaza y Valdés.

Arévalo, J.M. (2004). La tradición, el patrimonio y la identidad. Revista de Estudios Extremeños, 60(3), 925-956.

Ariño,A.(2012).Lapatrimonializacióndelaculturaysusparadojaspostmodernas.Antropología: Horizontes Patrimoniales, 209-230.

Carrasco (2008) La cultura en la seguridad alimentaria: expresiones, usos y desafíos para la investigación y la intervención. En S. Sandoval y J. Meléndez (eds.), Cultura y Seguridad Alimentaria (pp. 37-52). México: CIAD/Plaza y Valdés.

Comisión Económica para América Latina y el Caribe (CEPAL). (2004). oblación, envejecimiento y desarrollo. Recuperado de https://repositorio.cepal.org/bitstream/handle/11362/13059/ S044282_es.pdf?sequence=1Espeitx, E. (2004). Patrimonio alimentario y turismo: una relación singular. Pasos. Revista de turismo y patrimonio cultural, 2(2).

Food and Agriculture Organization (FAO). (2008). An introduction to the basic concepts of food security. Rome, Italy; FAO.

García (2017) Patrimonio cultural y seguridad alimentaria:tejiendo relaciones en torno a las cocinas tradicionales guayatunas (Tesis de Maestría) Universidad Pedagógica y Tecnológica de Colombia, Tunja

Gérard Lenclud, «La tradition n'est plus ce qu'elle était... », Terrain [En ligne], 9 | octobre 1987, mis en ligne le 19 juillet 2007, consulté le 04 décembre 2019. URL : http://journals. openedition.org/terrain/3195 ; DOI : 10.4000/terrain.3195.

Llull-Peñalba, J. (2005). Evolución del concepto y de la significación social del patrimonio cultural. Arte, Individuo y Sociedad, 17.

Medina, F.X. (2017). Reflexiones sobre el patrimonio y la alimentación desde las perspectivas cultural y turística. Anales de Antropología, 51 (2), 106-113.

Meléndez, J. y Cáñez, G.M. (2008). Cambios en la vida rural y en la cultura alimentaria campesina: San Pedro El Saucito, Sonora, México. Cultura y seguridad alimentaria, enfoques conceptuales, contexto global y experiencias locales, 263-300.

Ministerio de Cultura. (2012). Política para el Conocimiento, la Salvaguardia y el Fomento de la alimentación y las cocinas Tradicionales de Colombia. Recuperado http://www.mincultura. gov.co/areas/patrimonio/publicaciones/Documents/BBCTC, \%20tomo\%2017.\%20 Pol\%C3\%ADtica\%20para\%20el\%20conocimiento,\%20la\%20salvaguardia

Oceguera Parra, D. (2008). En las fronteras de la inseguridad alimentaria: subjetividad en familias michoacanas. S.A. Sandoval Godoy y J.M. Meléndez Torres (coords). Plaza y Valdés, Editores, CIAD. México.

Osorio, F.E., Jaramillo, O. y Orjuela, A. (2011). Jóvenes rurales: identidades y territorialidades contradictorias. Algunas reflexiones desde la realidad colombiana. Énfasis. Boletín del Observatorio Javeriano de Juventud, (1), 1-40.

Pérez-Martínez, M. y Pérez-Correa, E. (2002). El sector rural en Colombia y su crisis actual. Cuadernos de Desarrollo Rural, (48). 
Rodríguez, P. (2004). Envejecimiento en el mundo rural: Necesidades singulares, políticas específicas. Perfiles y Tendencias. Boletín sobre el envejecimiento, (11), 1-26. Recuperado de http://envejecimiento.csic.es/documentos/documentos/boletinsobreenvejec11.pdf

Rosas-Mantecón, A. (1998). El patrimonio cultural. Estudios contemporáneos. Presentación. Alteridades, 8(16), 3-9.

Salazar, R.D. (2001). Comida y cultura: identidad y significado en el mundo contemporáneo. Estudios de Asia y África, 83-108.

Smith, L. (2011). El "espejo patrimonial". ¿Ilusión narcisista o reflexiones múltiples?. Antípoda. Revista de Antropología y Arqueología, (12), 39-63.

Toledo, V.M. (1993). La racionalidad ecológica de la producción campesina. En E. Sevilla Guzmán y M. González de Molina (eds.), Ecología, campesinado e historia (pp. 197-218). Madrid: La Piqueta.

Urrutia, J. (2009, noviembre). Conferencia magistral: Fiestas e identidades. Fiestas y rituales. Presentada en Memorias X Encuentro, Lima, Perú. Recuperado de http://www.infoartes.pe/wp-content/uploads/2014/12/fiestas-y-rituales.pdf\#page=33 